\title{
O drama da subida interrompida: Lima Barreto na confluência das teorias raciais
}

\author{
Isabela da Hora Trindade ${ }^{1}$
}

\begin{abstract}
RESUMO: O objetivo desse artigo é refletir acerca de certos impasses da nossa história no que tange à identidade nacional, tendo em vista as anotações presentes no Diário Íntimo do escritor carioca Lima Barreto. Sublinharemos as anotações de foro intimo que soam, muitas vezes, como desabafos onde Lima demonstra seu enorme pesar em virtude, sobretudo, de sua condição mestiça. Nosso recorte se centrará na discussão racial - mais especificamente entre o final do século XIX e início do século seguinte.
\end{abstract}

ABSTRACT: The aim of this article is reflect about the directions given to the nation in view of the notes present in Diário Íntimo whose the native of Rio de Janeiro writer is Lima Barreto. We will underline, in particular, notes that sound of an intimate, often as outpourings where Lima shows his enormous regret, above all, about his racial condition. Our look will focus on racial discussing - more specifically between the late nineteenth and early of the next century.

PALAVRAS-CHAVE: Literatura Brasileira; Mestiçagem; Teorias Raciais; Lima Barreto; Diário Íntimo.

KEYWORDS: Brazilian Literature; Interbreeding; Racial Theories; Lima Barreto; Diário Íntimo.

No marco do debate atual ${ }^{2}$ acerca da questão das diferenças e das identidades culturais, abre-se caminho para repensarmos as politicas de ação afirmativa e, por conseguinte, compreendermos a atualidade das discussões sobre a noção de raça. Tais desdobramentos evidenciam o impacto causado pelas teorias raciais vindas da Europa, mais precisamente a contar do final do século XIX e início do XX, adotadas

1 Mestranda, Área de Estudos Comparados de Literaturas de Língua Portuguesa, DLCV, FFLCH, USP. Título da pesquisa: Lima Barreto: um intelectual d'avant-garde. Contato: Isa_dahora@yahoo.com.br.

2 Referimo-nos aqui às sessões de audiência pública, realizadas no início de março de 2010, que discutiram sobre a implementação do sistema de cotas nas Universidades públicas brasileiras, bem como à aprovação do Estatuto de Igualdade Racial pelo Senado. 
aqui na tentativa de construir uma identidade nacional respaldada cientificamente pela ciência européia.

A palavra raça é originária do italiano razza que, por sua vez, vem do latim ratio, "significa sorte, categoria, espécie", conforme define Munanga (2004, p. 17). Esse conceito usado inicialmente no campo das ciências naturais para classificar espécies animais e vegetais, gradativamente foi sendo ressignificado, até chegar a classificar a diversidade do gênero humano. Distribuir os individuos em classes demanda critérios bem definidos, foi quando, no século XVIII, estabeleceu-se a cor da pele como índice classificatório para a distinção das raças em branca, negra e amarela. No século seguinte, foram consideradas também a forma e a estrutura dos seres como ferramenta para comprovar as diferenças entre as raças.

Apresentadas essas primeiras observações, cabe explicitar que a análise pontual que ora será exposta, diz respeito à reflexão sobre os rumos dados à nação, considerando a diversidade racial premente em solo auriverde. Nosso recorte se centrará na discussão racial - mais especificamente entre o final do século XIX e início do século seguinte com o intuito de refletir sobre a constituição da identidade nacional, tendo em vista as anotações presentes no Diário Íntimo do escritor carioca Lima Barreto (1881-1922). Ao longo dos anos de escritura desse diário (escrito entre 1900-1921), o autor registrou não apenas os fatos miúdos do cotidiano, como também suas impressões de leituras e, somem-se a isso, anotações de foro íntimo que soam, muitas vezes, como desabafos onde Lima demonstra seu enorme pesar em virtude, sobretudo, de sua condição racial. Foi justamente esse último tipo de registro que nos instigou a especular de que maneira esse autor concebe a sociedade brasileira no tocante ao complexo e escorregadio problema da nossa identidade. Essas são as principais questões que envolvem o percurso desse estudo.

A abolição da escravatura em 1888 e, no ano seguinte, a Proclamação da República inevitavelmente instauraram mudanças 
econômicas, sociais, políticas e culturais no Brasil, sobretudo no Rio de Janeiro, capital do país.

Foi por aqueles tempos também que o negro fora colocado em evidência, uma vez que passava da condição de ex-escravo ao status de cidadão livre, logo, aparentemente teria os mesmos direitos que os demais cidadãos brasileiros. Diante desse fato, uma questão se impôs à sociedade brasileira: como inserir os escravos recém libertos nesta sociedade hierarquizada agrilhoada por uma estrutura escravista? A saída para esse impasse foi a adoção negociada das teorias raciais formuladas por teóricos europeus originalmente para justificar o imperialismo do velho continente:

Como acontece geralmente na maioria dos países colonizados, a elite brasileira do fim do século XIX e início do século XX foi buscar seus quadros de pensamento na ciência europeia ocidental, tida como desenvolvida, para poder não apenas teorizar e explicar a situação racial do seu país, mas também, e sobretudo, propor caminhos para a construção de sua nacionalidade, tida como problemática por causa da diversidade racial. (MUNANGA, 2008, p. 47)

No Brasil, as teorias raciais tiveram seu apogeu entre 1870-1930, servindo às elites de modo a moldar as ações políticas. Nesse contexto, Ventura destaca as contradições da aplicação desses modelos num país essencialmente mestiço:

O racismo científico assumiu uma função interna, não coincidente com os interesses imperialistas, e se transformou em instrumento conservador e autoritário de definição da identidade social da classe senhoril e dos grupos dirigentes, perante uma população considerada étnica e culturalmente inferior. (VENTURA, 1991, p. 60)

A descoberta das diferenças entre os homens foi a base para a formulação das teorias que instituíram a classificação das raças em superiores e inferiores: "Existem raças puras, e, portanto distintas das outras: ou seja, há diferenças biológicas significativas entre os grupos e os indivíduos que os compõem" (MEMMI, 1993, p. 14), argumentos que 
serviram a teóricos como Buffon, Buckle e Gobineau, nomes importantes para o estabelecimento do pensamento racista.

O naturalista francês Buffon (1707-1788) analisou o continente americano a partir de uma perspectiva negativa, pois, segundo ele, o cruzamento entre espécies diferentes levaria à degeneração. Acreditava que a cor branca era a original do ser humano, por isso apostava no branqueamento. Para ele, os homens descendiam todos de um gênero comum. Em contrapartida, Gobineau (1816-1882), diplomata francês que viveu no Brasil entre 1869 e 1870, negava a origem comum da humanidade, acreditava na existência de raças separadas. Favorável ao determinismo racial, afirmava que as nações mestiças não eram civilizáveis, por essa razão prevê o aniquilamento dos mestiços brasileiros num período de 200 anos (RAEDERS, 1988, p. 241).

As teorias formuladas por Buffon e Gobineau resultam de visões diferentes: o primeiro identifica-se à visão monogenista, já o segundo ao poligenismo. De acordo com os monogenistas, o homem teria uma origem comum, sendo que as diferenças entre os humanos seriam resultado de um maior ou menor grau de degeneração ou de perfectibilidade. Os poligenistas, por sua vez, postulavam que as diferenças raciais configuravam-se em razão da existência de diferentes raças. Nesse sentido, enalteciam as raças puras e consideravam o cruzamento interracial um erro, pois a miscigenação significava degeneração não só racial, mas também social. Assim, "Ter a pele clara, provir do "sangue" europeu, não ter mesclas com as raças "inferiores", principalmente a negra, constituía, segundo as ideias da época, o distintivo da nobreza, da superioridade social e moral" (MUNANGA, 2008, p. 63).

Buckle (1821-1862), representante do determinismo geográfico, atentava para as condições climáticas, para a vegetação e o solo a fim de classificar determinado país e, por extensão, seu povo. Desse modo, o desenvolvimento de uma nação estava condicionado ao meio físico.

O resultado do uso dessas teorias raciais no cenário brasileiro foi a ideologia do ideal de branqueamento que se daria por meio do 
processo de miscigenação, considerando-se a superioridade da raça branca. Diante de um país, cuja nação era constituída em grande parte por negros e mestiços, a saída foi optar pelo cruzamento interracial (negro $\mathrm{x}$ branco) na tentativa de abrandar a potencialidade dos caracteres das raças inferiores. A intervenção de Lacerda, então diretor do Museu Nacional do Rio de Janeiro, no Primeiro Congresso Universal das Raças realizado em Londres em 1911, oficializou uma opção brasileira pelo ideal de branqueamento. Vale acompanhar nas palavras do nosso representante, as previsões candentes no horizonte nacional:

A seleção sexual continua, aperfeiçoando-se sempre ao subjugar o atavismo e ao purgar os descendentes dos mestiços de todos os traços característicos dos negros. Graças a esse procedimento de redução étnica, é lógico supor que, no espaço de um novo século, os mestiços desaparecerão do Brasil, fato que coincidirá com a extinção paralela da raça negra entre nós. (LACERDA, Mimeo)

Lacerda enfatiza as mudanças pelas quais passariam a população mestiça brasileira em virtude das correntes de imigração européia que corroborariam para o aumento dos caracteres brancos em nossa população. A fusão das raças levaria à fusão cultural, ou seja, a imagem do brasileiro se faria a partir da incorporação das culturas européias, indígenas e africanas. Porém, aqueles constituídos por sangue misto ficaram à margem da sociedade, impedidos de ascender socialmente justamente pelo caráter mestiço.

Esse breve panorama dos modelos racistas dimensiona o peso que tais teorias tiveram no Brasil e, por conseguinte, na vida de Lima Barreto que, por ser mestiço, já nasceu marcado pela inferioridade racial. São várias as notas que demonstram claramente o profundo desajustamento de Lima em razão da ambiguidade criada pelo seu status social enquanto mulato pobre e sua condição intelectual de homem de letras:

$\mathrm{Eu}$, entretanto, penso me ter salvo. Eu tenho muita simpatia pela gente pobre do Brasil, especialmente pelos de cor, mas não me é possivel transformar essa simpatia 
literária, artística, por assim dizer em vida comum com eles, pelo menos com os que vivo, que, sem reconhecerem a minha superioridade, absolutamente não tem por mim nenhum respeito e nenhum amor que lhes fizesse obedecer cegamente. (BARRETO, 1956, p. 76)

Lima, letrado consoante aos padrões culturais europeus, intelectualmente sente-se superior, como é possivel observarmos no excerto supracitado. Sob esse prisma, detecta-se aí uma tensão mantida, pois ao mesmo tempo em que o escritor carioca assume-se enquanto negro, distancia-se das gentes de cor, fato que revela $o$ desajuste entre sua figura de intelectual e os membros de sua família. Observamos que, embora Lima tente salvar-se dos estigmas, não deixa de corroborar para a manutenção do abismo criado entre os brancos e "os de cor" por aqueles que manipulam a ciência. Contudo, sua condição racial sempre fora colocada como fator mais significativo perante a sociedade, razão pela qual o autor nunca foi vinculado à elite de escritores brasileiros. Silva expõe claramente essa ambigüidade entre cor e classe ao focalizar as trajetórias de Lima Barreto e Cruz de Souza:

Cruz e Lima não eram indivíduos aculturados, ou seja, não saíram de uma cultura, com padrões definidos, para outra que apresentasse diferentes concepções de vida. Como brasileiros letrados da época, desenvolveram-se dentro dos adaptados padrões culturais europeus. Contudo, a pobreza e a situação racial do período em que viveram, submetendo-os a inúmeros constrangimentos e restrições, indicam que, por aquelas circunstâncias, estariam vinculados à cultura popular, pelo menos nos primeiros anos de vida, além de tê-las como referência pelos vínculos familiares. Contudo, o vetor de suas pretensões, muito cedo, foi o da cultura letrada. O desenvolvimento do exercício da escrita levou-os a dirigir suas atenções para as brechas da ideologia estética e seus pontos de desarticulação. Sabiam que as formas literárias tinham seus significados sociais, bem como que elas operavam no sentido de traduzir a conformação da hierarquia. (SILVA, 2005, p. 188)

Lima sabia muito bem das benesses que poderia gozar caso não estivesse condenado ao estigma racial de sua cor, ainda assim insiste em articular-se num espaço ambivalente - o da cultura letrada, embora 
seu espaço original fosse o subúrbio. A escrita no diário ou na ficção permitiu-lhe ultrapassar as fronteiras desses espaços, extrapolar padrões intelectuais, sociais, literários; possibilitando-o tudo dizer, expondo suas preocupações estéticas e pessoais livres de qualquer censura.

Não obstante as queixas em virtude das barreiras encontradas dada sua condição racial, Lima mostra-se absolutamente consciente de sua cor, ou seja, ele se aceita enquanto mestiço, não deseja embranquecer para ser reconhecido. Nesse sentido, coloca-se na contramão do sistema, pois almeja a glória embora seja mulato. Ele, muito habilmente, compreendeu e sentiu o peso do passado de sua gente $^{3}$ e, por conseguinte, das teorias raciais vindas da Europa que renegavam aos seus a condição de cidadão mesmo num país de regime republicano:

\begin{abstract}
Vai se estendendo, pelo mundo, a noção de que há umas certas raças superiores e umas outras inferiores, e que essa inferioridade, longe de ser transitória, é eterna e intrinseca à própria estrutura da raça. Diz-se ainda mais: que as misturas entre essas raças são um vício social, uma praga e não sei que coisa feia mais. (BARRETO, 1956, p. 110)
\end{abstract}

Aqui, os negros seriam os malogrados, condenados à miséria e à barbárie de acordo com os postulados europeus. Nesse cenário, Lima elucida "a covardia intelectual de que [nós brasileiros] estamos apossados em face dos grandes nomes da Europa" (BARRETO, 1956, p. 111). Por um lado, esboça uma crítica às teorias raciais, todavia, seu posicionamento esbarra no discurso oficial favorável ao branqueamento, visto como saida aos males da mestiçagem. Por outro lado, a observação do comportamento dos familiares de Lima quase o empareda, pois à medida que combate os postulados científicos que afirmam a inferioridade do negro, vê em sua família indícios comprobatórios que poderiam atestar a validade desses postulados: a loucura do pai $^{4}$, a

\footnotetext{
${ }^{3}$ As avós de Lima, tanto materna (Geraldina Leocádia), quanto paterna (Carlota Maria dos Anjos) eram negras e ex-escravas.

${ }^{4}$ Em 1902, João Henriques, pai de Lima Barreto, começou a padecer dos primeiros
} 
tendência do irmão para o roubo e da irmã para a prostituição, conforme comenta nas páginas do Diário. Estende ainda essa impressão: "Há em minha gente toda uma tendência baixa, vulgar, sórdida” (BARRETO, 1956, p. 76). Lúcido, sensível e ressentido, Lima experimenta o drama daquele que vivencia a urgência de transcender as marcas impressas pela esfera científica bem como pela realidade concreta de sua gente.

Nesse momento, um negro que ousasse aventurar-se como escritor, oficio reconhecidamente dos brancos, conforme assinala Silva (2005, p. 55), "será encarado como alguém investido de uma pressuposta inferioridade". Não à toa, a Lima ofereceram o desprezo intelectual que, além de afastá-lo das glórias almejadas, ainda o levou à desgraça pessoal. A possibilidade de ascensão para um autor negro, como expõe Bosi (2002, p. 188), dependia da combinação "de talento pessoal e apadrinhamento sustentado no momento oportuno". Segundo o autor, alguns exemplos que deram certo foram Luís Gama, Machado de Assis, André Rebouças e José do Patrocínio. Já o caso de Lima, Bosi classifica como "o drama da subida precocemente interrompida" (Ibidem, p. 188). E completa: "Ingressando na vida adulta, o jovem promissor se vê desamparado dos primeiros apoios e cai na esfera competitiva de um meio onde vicejam a hostilidade ou o desprezo pelo pobre e, em particular, pelo negro ou mestiço" (Ibidem, p. 188).

Com efeito, Lima nunca manteve relação afetiva com o padrinho, o Visconde de Ouro Preto, que custeou seus primeiros estudos. Rompeu logo cedo com ele magoado pelo fato do padrinho nunca ter lhe dedicado um gesto de carinho: "Ressentido, o afilhado passou a evitar a presença antipática, que só lhe fazia avivar a situação humilhante de protegido. Isto aconteceu em 1902 ou 1903" (BARBOSA, 2003, p. 120).

Todos os postulados científicos aqui expostos chegaram ao Brasil e, como não poderia deixar de ser, foram objeto de reflexão de Lima que se via violentamente atingido por essas teorias: "Se a feição, o peso, a forma do crânio nada denota quanto a inteligência e vigor mental entre delírios. 
indivíduos da raça branca, porque excomungará o negro?” (BARRETO, 1956, p. 61), questionava-se ele aos vinte e três anos de idade. Aqui, o jovem Lima faz uma referência expressa aos estudos ligados ao campo da Craniometria, indagando-se sobre a validade desses estudos. No ano seguinte, Lima faria um comentário ainda mais explícito acerca dessas teorias de modo acentuadamente contestador:

Os séculos que passaram não tiveram opinião diversa a nosso respeito - é verdade; mas, desprovida de qualquer base séria, as suas sentenças não ofereciam o minimo perigo. Era o preconceito; hoje é o conceito. Esmagadoras provas experimentais endossam-no. Se F. tem 0,02 $\mathrm{m}$ a mais no eixo maior da oval de sua cabeça, não é inferior em relação a $B$, que tem menos, porque ambos são da mesma raça; contudo, em se tratando de raças diferentes, está aí um critério de superioridade. As mensurações mais idiotas são feitas, e, pelo complacente critério do sistema métrico, os grandes sábios estabelecem superioridades e inferioridades. Não contentes com isso, buscam outros dados, de touristes imbecis e de aventureiros da mais baixa honestidade. (BARRETO, 1956, p. 111)

O sentimento de indignação em virtude da aceitação passiva e incontestada dos modelos europeus assinala o quanto custou a Lima conviver com o peso das teorias racistas - "Desviei a corrente natural de minha vida, escondi-me em mim mesmo e fiquei a sofrer para sempre ..." (BARRETO, 1956, p. 112). Entretanto, ele percebeu claramente a insensatez desses modelos afirmando-se enquanto mulato consciente de seus predicados intelectuais:

Mas, hoje! Hoje! Já posso alguma coisa e amanhã poderei mais e mais. Não pararei nunca, não me deterei; nem a miséria, as perseguições, as descomposturas me deterão. Sacudi para longe o fantasma do medo; sou forte, penso, tenho coragem... Nada! Nada! Nada! É que senti que a ciência não é assim um cochicho de Deus aos homens da Europa sobre a misteriosa organização do mundo. (BARRETO, 1956, p. 112)

Nesse pungente desabafo, entrevemos a posição ímpar de Lima que não adere irrefletidamente às ideias estrangeiras, antes pondera, 
discute, avalia para então legitimar ou não o pensamento europeu. É possivel percebermos que ele reflete tentando encontrar o lugar daquilo que veio de fora no âmbito do contexto brasileiro. Nesse sentido, condena manifestadamente a adoção das teorias racistas importadas da Europa pela elite brasileira como forma de validar o tratamento dispensado aos negros e aos mestiços. Entendia que tais teorias não cabiam na realidade cultural de nosso país, pois "concebia a sociedade brasileira como o fruto da combinação de diferentes etnias e que, em virtude mesmo dessa mestiçagem, havia atingido um grau elevado de intimidade e adaptação à natureza tropical e vigente do país" (SEVCENKO, 2003, p. 210).

Não causa espanto, pois, como assinala Carvalho, que as preocupações estéticas de Lima, avesso à imagem fútil da Belle Époque carioca, destoassem dos olhares voltados irrestritamente para o cenário europeu:

O brilho republicano expressou-se em fórmulas européias, especialmente parisienses. Mais que nunca, o mundo literário voltou-se para Paris, os poetas sonhavam viver em Paris e, sobretudo, morrer em Paris. Com poucas exceções, como o mulato Lima Barreto e o caboclo Euclides da Cunha, os literatos se dedicaram a produzir para o sorriso da elite carioca, com as antenas estéticas voltadas para a Europa. (CARVALHO, 1987, p. 39)

Conforme as notas de Lima revelam, as reflexões acerca de sua condição racial demonstram que ele sentiu-se alvo dos modelos racistas instituídos como verdades absolutas e incontestáveis durante o curto período de sua vida. Assim, ele se volta para aquilo que nos é próprio, ou seja, para a realidade brasileira contemplando os elementos locais, dos quais se sobressaem as origens mestiças.

Colocando-se antagonicamente à frente de seu tempo, Lima não se mostra em momento algum deslumbrado pela cultura européia: "Eu veria a Vitória de Samotrácia com o mesmo olhar e a mesma emoção com que vejo um manipanso africano. São documentos sociais ambos" (BARRETO, 1956, p. 206). 
Com efeito, não estamos diante de um autor embasbacado pelo fetiche criado em torno de tudo que provinha da cultura européia, num momento em que se agraciavam os modelos científicos, sociais e políticos do velho mundo. Lima impõe-se contrariamente ousando mesmo duvidar da supremacia creditada à Europa. Desenha-se, pela perspectiva particular dessa visão dissonante, uma marca de resistência desse mulato cindido pela ambiguidade entre cor e classe que se manteve à margem da sociedade brasileira pautada pelo determinismo racial.

Diante do exposto, cumpre-se ressaltar em nosso tempo a ressonância dos desabafos denunciativos presentes no Diário Íntimo. É inegável que permanecemos numa sociedade cujas desigualdades originárias do quesito raça não apenas são expressivas como teimam em persistirem permeando todos os setores sociais camuflados, muitas vezes, pela bandeira da igualdade e da não racialização do povo brasileiro. Não é de se estranhar, portanto, que tal prática perpetuará a exclusão de tantos outros mestiços e negros que, assim como Lima Barreto, sofreram e sofrem as consequências do não reconhecimento das diferenças presentes no cerne do tecido social, em favor do discurso apaziguador da democracia racial.

\section{Referências bibliográficas}

BARBOSA, Francisco de Assis. A vida de Lima Barreto. Rio de Janeiro: José Olympio, 2003.

BARRETO, Lima. Diário Íntimo. São Paulo: Editora Brasiliense, 1956.

BOSI, Alfredo. Literatura e Resistência. São Paulo: Companhia da Letras, 2002. 
CARVALHO, José Murilo de. Os bestializados. O Rio de Janeiro e a República que não foi. São Paulo: Companhia das Letras, 1987.

LACERDA, João Batista. Sur le Métis au Brésil. (Mímeo).

MEMMI, Albert. O Racismo. Lisboa: Caminho, 1993.

MUNANGA, Kabengele. Rediscutindo a mestiçagem no Brasil: Identidade nacional versus identidade negra. Belo Horizonte: Autêntica, 2008.

- Uma abordagem conceitual das noções de raça, racismo, identidade e etnia. In: BRANDÃO, André Augusto P. Programa de educação sobre o negro na sociedade brasileira. Rio de Janeiro: EDUFF, 2004.

RAEDERS, Georges. O Inimigo cordial do Brasil. Rio de Janeiro: Paz e Terra, 1988.

SEVCENKO, Nicolau. Literatura como missão: Tensões sociais e criação cultural na Primeira República. São Paulo: Companhia das Letras, 2003.

SILVA, Luiz. A Consciência do Impacto nas Obras de Cruz e Souza e de Lima Barreto. Campinas, 2005. 232 f. Tese (Doutorado) - Instituto de Estudos da Linguagem, Universidade de Campinas.

VENTURA, Roberto. Estilo Tropical: História Cultural e Polêmicas Literárias no Brasil: 1870-1914. São Paulo: Companhia das Letras, 1991. 
Revista Crioula - n 9 - maio de 2011 